\title{
Barriers to Mesalamine Adherence in Patients with Inflammatory Bowel Disease: A Qualitative Analysis
}

\author{
Jennifer Devlen, PhD; Kathleen Beusterien, MPH; Linnette Yen, MA, MS \\ Awais Ahmed, MBBS; Adam S. Cheifetz, MD; and Alan C. Moss, MD
}

\begin{abstract}
BACKGROUND: The causes for nonadherence to mesalamine in patients with inflammatory bowel disease (IBD) have been characterized using mostly indirect methods. Patient-reported barriers are lacking in this population.

OBJECTIVE: To identify patient-reported barriers to mesalamine adherence through direct interviews.
\end{abstract}

METHODS: Focus groups and one-on-one interviews were undertaken in adult patients with IBD. Transcripts from the focus groups and interviews were analyzed to identify themes and links between these themes, assisted by qualitative data software MaxQDA.

RESULTS: Of 27 patients participating, 21 (78\%) had ulcerative colitis, and $6(22 \%)$ had Crohn's disease. Their self-reported adherence ranged from complete adherence $(n=3)$ to intermittent nonadherence $(n=24)$. Patients frequently indicated that they were resistant to taking medications for their condition. The barriers to adherence that emerged from interviews could be categorized under a number of themes: competing priorities, social stigma, refill inconvenience, costs, efficacy values, side effects, and pill characteristics. Efficacy values reported to influence adherence included doubts about efficacy, consequences of missed doses, and doubts about need for maintenance medication. Pill characteristics reported as barriers included pill size and pill frequency. Despite use of electronic prescribing, obtaining refills was reported as an obstacle to adherence in this cohort. Decanting of pills to multiple containers to increase accessibility was also reported.

CONCLUSIONS: Patients with both ulcerative colitis and Crohn's disease report a number of common barriers to mesalamine adherence. Factors in medication-taking behavior and beliefs were reported in this study that may have implications for strategies to improve adherence by health care providers.

J Manag Care Pharm. 2014;20(3):309-14

Copyright $\odot 2014$, Academy of Managed Care Pharmacy. All rights reserved.

\section{What is already known about this subject}

- Nonadherence to mesalamine is common in patients with inflammatory bowel disease (IBD).

- Adherence behavior is influenced by many factors.

- Data on patient-reported barriers to adherence in IBD are lacking.

\section{What this study adds}

- Patients with IBD report a number of common themes that impact their adherence.

- Doubts about efficacy, concern about side effects, and pill characteristics lead to nonadherence in these patients; these factors could be targeted by providers for intervention.

- Despite use of electronic prescribing, refills remain a barrier to adherence in these patients.
7 he chronic nature of inflammatory bowel disease (IBD) necessitates the use of long-term medications to maintain clinical remission. As with many chronic diseases, adherence or persistence to maintenance medications is low, reportedly as low as $40 \%$ in patients with ulcerative colitis (UC) who are prescribed mesalamine., ${ }^{1,2}$ Low adherence has been associated with a higher risk of disease relapse, higher health care costs, and a possible greater risk of colon cancer for patients. ${ }^{3-5}$ As a consequence, there has been an effort in recent years to identify risk factors for nonadherence in patients with IBD, and to target interventions to these factors. ${ }^{6-8}$

Numerous analyses of payer databases and clinical practice cohorts have identified subject characteristics associated with low adherence, including gender, marital status, and pill burden. ${ }^{9}$ However, the strength of these links is inconsistent across different studies, and many factors are not amenable to intervention by health care providers. ${ }^{10}$ Broad, simplistic approaches to improving adherence, such as telephone reminders or education, have yielded mixed results, suggesting that adherence behavior is a more complex phenomenon. ${ }^{11-15}$ Recent systematic reviews of existing intervention strategies have highlighted their limitations and the need for a further understanding of this problem. ${ }^{16,17}$

Our understanding of adherence behavior in patients with IBD is thus incomplete, as the methodology of many studies only allows examination of surrogate markers of beliefs or behaviors, such as gender or socioeconomic status, rather than patient-reported barriers to adherence. ${ }^{2,18,19}$ Data from other diseases have identified patient-reported barriers to adherence, but these results may not be applicable to the IBD population because of the different demographic distributions of these conditions; the concerns of a woman aged 50 years with breast cancer may not mirror those of a college student aged 20 years with colitis. ${ }^{20}$ Qualitative-based research has illustrated that enhancing medication-taking behavior in patients with IBD requires a more in-depth examination of patients' motivations. $^{21-23}$ Several patient-reported outcome measures have been developed for IBD with the goal of quantifying the holistic effects of these conditions, but they lack coverage with respect to adherence attitudes. ${ }^{24,25}$

The objective of this study was to understand patients' attitudes toward adherence in order to help inform a conceptual model of patients' barriers to adherence. 


\section{Methods}

This was a qualitative study in which focus groups or one-onone interviews were conducted with adults suffering from UC or Crohn's disease (CD) to identify the impact of IBD and its management, excluding surgery. Both methods were used to generate a comprehensive capture of patient-derived themes.

\section{Qualitative Research with Patients}

Participants were recruited through a tertiary clinical site specializing in the treatment of IBD. Patients were eligible if they were aged 18 years or older, had mild or moderate UC or $\mathrm{CD}$ in clinical remission, and were currently only prescribed mesalamine for maintenance of their IBD. All prescriptions and refills were routed via electronic prescribing for this practice. Using a standardized moderator guide, a trained interviewer asked open-ended questions to elicit patients' experiences of adherence to their IBD medications. The moderator guide and questions were developed by an IBD specialist (Moss) and qualitative researcher (Devlen) with expertise in adherence, after studying previously published examples. Both focus groups and interviews were used to ensure that no one method biased the patient-reported themes, and different patients were used for both methods. We planned 4 focus groups and 10 individual interviews a priori, consistent with general recommendations on sample size for qualitative research. Data were collected until information saturation was attained, that is, until no new information was being identified. The focus groups were convened, and interviews were conducted at the Beth Deaconess Medical Center, Boston, Massachusetts, where full institutional review board approval was obtained. All patients gave written informed consent to participate and received a small payment for their time after the interviews were completed.

\section{Analyses}

Transcripts from the focus groups and one-on-one interviews were analyzed by a single analyst following the principles of grounded theory to identify themes and possible links between themes. ${ }^{26}$ Qualitative data analysis software MaxQDA version 10.0 (VERBI GmbH, Berlin, Germany) was used to code and facilitate organization of the data. In accordance with standard qualitative data analysis, a saturation table was constructed to assess data saturation. ${ }^{27}$

\section{Results}

A total of 27 patients (4 focus groups comprising 2-6 participants each and 10 one-on-one interviews) participated. The mean age was 31.5 years (range 20-59); 52\% ( $n=14)$ of patients were male; and $78 \%(\mathrm{n}=21)$ of patients had UC, while $22 \%(n=6)$ of patients had CD (Table 1$)$. At the time of the interviews, 21 out of 27 patients were in clinical remission (based on Simple Colitis Clinical Activity Index <2), but this cohort was disease-experienced. The mean disease dura-

\section{TABLE 1 Participant Characteristics}

\begin{tabular}{l|c}
\hline Characteristic & $\mathbf{N}=27$ \\
\hline Age (years) & $31.5 \pm 9$ \\
\hline Mean \pm SD & 20,59 \\
\hline Minimum, maximum & $14(52)$ \\
\hline Gender (\%) & $13(48)$ \\
\hline Male & \\
\hline Female & $6.5 \pm 6$ \\
\hline Disease duration (years) & 1,20 \\
\hline Mean \pm SD & $21(78)$ \\
\hline Minimum, maximum & $6(22)$ \\
\hline Diagnosis (\%) & $12(44)$ \\
\hline Ulcerative colitis & $11(41)$ \\
\hline Crohn's disease & $4(15)$ \\
\hline Current maintenance medication (\%) & \\
\hline Asacol & $15(55)$ \\
\hline Lialda & $9(33)$ \\
\hline Pentasa & $3(12)$ \\
\hline Mesalamine schedule (\%) & $13(48)$ \\
\hline Once per day & \\
\hline Twice per day & \\
\hline Three times per day & \\
\hline Concomitant immunomodulators (\%) & \\
\hline SD standard deviation. &
\end{tabular}

tion was 7 years, and 13 out of 27 were also on maintenance immunomodulators or biologics because of prior moderate to severe disease. Reported adherence ranged from total adherence $(n=3)$ to intermittent nonadherence $(n=24)$. The focus groups were conducted prior to the individual interviews, and the evaluation of information saturation indicated that no new codes (themes) were added after the eighth one-on-one interview, demonstrating data saturation. A comparison of themes did not identify any differences in impacts between UC and CD patients.

From these transcripts, the barriers to adherence that patients reported were categorized under a number of themes: competing priorities, social stigma, refill inconvenience, costs, efficacy values, side effects, and pill characteristics. Sample quotations from some of these themes are presented in Table 2.

\section{Competing Priorities}

Forgetting caused by competing tasks was the most common reason given for not taking medication as prescribed. A representative quote from one interview noted: "I'd never ever remember to take during the day because just doing all these other things and, to me, it's easier to take it at home. Once you get to work or school or whatever... your mind is off that."

There were a variety of circumstances that interfered with remembering. These included being busy or distracted by work or other activities, or a change in routine on weekends and vacations, where the usual triggers at home that acted as 


\section{TABLE 2 Sample Quotations from Each Theme}

\begin{tabular}{|c|c|}
\hline \multicolumn{2}{|c|}{ 1. Competing Priorities } \\
\hline Busy/occupied & $\begin{array}{l}\text { Patient \#4: "Yeah. I've never intentionally not taken it. Sometimes, if I get really busy I might just_-I don't know if I really want to get } \\
\text { out of the house or like I'm late in the morning I'll just forget it and if that happens.... It's kind of just general forgetfulness for me." }\end{array}$ \\
\hline Weekends & $\begin{array}{l}\text { Patient \#10: "Normally the weekends if there's a lot going on because you don't have that routine, you don't get up and go to work or } \\
\text { school. You know, it's the weekends. You sleep in a little, someone calls you, you go out to brunch or something. You don't remember." }\end{array}$ \\
\hline Away from home & $\begin{array}{l}\text { Patient \#5: "Like, for me, I travel. So if I'm traveling and if for some reason I'm just an idiot and did my math wrong, like, if I needed } \\
15 \text { and I brought } 12 \text {. It's usually stuff-it's to her point, I mean, whenever you go somewhere you have to bring all of your medicine, } \\
\text { you know. I'm that guy in the airport line jingling my carry-on bag, you know? Instead of bringing } 5 \text { different pill bottles, I just } \\
\text { throw it all in one. So for me it's when I'm going somewhere. Like when I'm not going to be at home I usually forget it because you } \\
\text { just.... You don't-maybe you're somewhere longer than you thought you were. It's always planning, planning, planning." }\end{array}$ \\
\hline $\begin{array}{l}\text { General } \\
\text { disorganization }\end{array}$ & $\begin{array}{l}\text { Patient \#7: "I have a terrible memory so I may have forgotten it and just not realized it later. But, yeah, other than that I don't think I } \\
\text { have. I take it a couple hours later when I remember." }\end{array}$ \\
\hline \multicolumn{2}{|l|}{ 2. Social Stigma } \\
\hline Embarrassment & $\begin{array}{l}\text { Patient \#22: "Yeah, I mean, I guess I don't like to take it in front of people, especially people who don't know that I have ulcerative } \\
\text { colitis and, you know, would not know why I'm taking medicine. So if I'm at, say, if I'm at a meeting during the day, and it's time } \\
\text { for me to take my medicine, I'll take it after the meeting. But usually those don't stop me from taking it on time or within an hour of } \\
\text { when I'm supposed to take it." }\end{array}$ \\
\hline Peer pressure & $\begin{array}{l}\text { Patient \#2: "And I'm still in college. I have a roommate, so all of my pills are in my room, and my roommate is always asleep before } \\
\text { me, so I feel really bad shaking all my pill bottles. So, sometimes I don't take them because I don't want to wake her up, which is } \\
\text { kind of silly, but I feel really bad." }\end{array}$ \\
\hline Stigma & $\begin{array}{l}\text { Patient \#15: "I find that sometimes it's just awkward. If it's during the day when you're out and, you know, been on a date or something } \\
\text { and you're like, 'Oh, time to take my medicine.' How do I do this discreetly without someone being 'I'm popping } 4 \text { pills right now,' } \\
\text { or.... It's just a little bit weird. I mean, like I said, most of my friends are very used to me just constantly stopping to take medicine but...." }\end{array}$ \\
\hline \multicolumn{2}{|c|}{ 3. Refill Inconvenience } \\
\hline $\begin{array}{l}\text { Refilling } \\
\text { prescriptions }\end{array}$ & Patient \#6: "Or when you go to refill it, and you've passed the pharmacy hours or something. You just forgot, or it wasn't convenient." \\
\hline Forgetfulness & $\begin{array}{l}\text { \#23: "I think I didn't necessarily forget, I just forgot to pick up my prescription on time, so I missed the day in between the } \\
\text { ut other than that, I don't forget that one either." }\end{array}$ \\
\hline
\end{tabular}

\begin{tabular}{|c|c|}
\hline \multicolumn{2}{|l|}{ 4. Costs } \\
\hline & $\begin{array}{l}\text { Patient \#24: "Let's see. I don't know if I can get it off the top of my head. I mean, they're relatively cheap independently, but I just- } \\
\text { continuously I think it just adds up. I would pay that. That's nothing. I'd much rather pay that than have to be symptomatic. But with } \\
\text { symptoms probably going in remission I'd be more inclined probably to subside [sic] taking them and paying for them and stuff." }\end{array}$ \\
\hline \multicolumn{2}{|l|}{ 5. Efficacy Values } \\
\hline \multirow{2}{*}{$\begin{array}{l}\text { Time to } \\
\text { response }\end{array}$} & Interviewer: "So, why did you switch off of the mesalamine?" \\
\hline & $\begin{array}{l}\text { Patient \#19: "I kind of gave up on it. I didn't really-I was taking these pills, and I was on it for a while. I can't even tell you how long } \\
\text { I was on it. And, I just felt I doubted that it was even doing anything for me. So I just stopped taking it." }\end{array}$ \\
\hline \multirow{2}{*}{$\begin{array}{l}\text { Testing necessity } \\
\text { of medication }\end{array}$} & Interviewer: "Do you stop taking your meds, then, when you're in remission?" \\
\hline & $\begin{array}{l}\text { Patient \#3: "Sometimes. Yeah...it just...makes me feel like I can do this. I'm fine. But then I get to see, you know, what's medication } \\
\text { and what's not." }\end{array}$ \\
\hline $\begin{array}{l}\text { Insufficient } \\
\text { understanding } \\
\text { of benefits of } \\
\text { therapy }\end{array}$ & $\begin{array}{l}\text { Patient \#27: "I don't mean to insult my previous physician, but I don't think that I was-it was sort of-I wasn't given a lot of good } \\
\text { direction in terms of how to take care of myself. So it was, you know a lot-there's no specific diet, you know? There's no magic diet, } \\
\text { but there are things that can help, that are shown to help, and they're shown to not help overall, and I wasn't shown that. Maybe I'll } \\
\text { just do this to help, maybe I'll take the pills every once in a while just to help it...I thought that it was just a one-time deal. If I had } \\
\text { known that it was really possible that I could flare up again, then I would have taken it." }\end{array}$ \\
\hline
\end{tabular}

\section{Pill Characteristics}

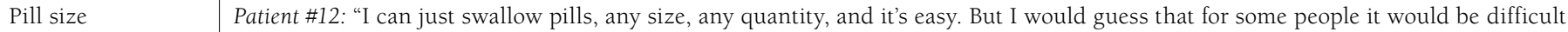
to take the large pills the way I do it. And, I've heard that people have a hard time with it. So I would say the shape and size of the medication could definitely affect some people taking their medication."

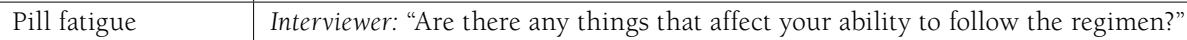

Patient \#3: "Probably my ego. That's really the biggest thing...I just have to take it in the morning, and then every once in awhile I'm just sick of taking it."

\section{Side Effects}

Patient \#26: "The creatine level was a little bit elevated and...one of the doctors suggested that could be related to

[mesalamine]. So I'm chasing that. And if there is, then I would go off the [mesalamine] because potentially I would need to, you know, protect the kidney function."

reminders were gone. Being preoccupied, particularly during the day, meant that the midday dose was often forgotten. Morning doses might be missed in the early morning rush, and in the evening, tiredness and social activities interfered with remembering the nighttime dose. The necessity for organization and advanced planning to pack medications when necessary was apparent, and many patients reported lapses in planning. Notably, some patients have developed interesting 
rituals to aid their adherence: "I just put them in...these little bags, these reusable bags-so, if for some reason I forget, I just fill up the bag for the whole week, so that way I know that I took it that morning. Because I get up so early...I will forget. So, every once in a while, I will try to like take it from the bottle, and then the bag will be full, and I'll be, like, did I take those? Did I not take those? So there's like a chance where there's days... maybe I just took 6 and maybe I took 0."

\section{Social Stigma}

Sometimes it was impractical, socially awkward, or embarrassing to take medication on time, or patients did not want others to question their physical well-being. Since a proportion of this population is frequently at college, or beginning new relationships, the stigma of disease from taking medications was commonly reported: "I guess I don't like to take it in front of people, especially people who don't know that I have ulcerative colitis and, you know, would not know why l'm taking medicine."

Skipping medication on date nights, or when sleeping over with friends, emerged frequently in interviews for these reasons.

\section{Refill Inconvenience}

Hassles related to refilling prescriptions might temporarily interfere with adherence, and cost was a significant concern for a few patients. This problem often was referred to in similar terms to competing tasks; the inconvenience of having to fit a pharmacy visit into daily schedules or call physician offices for refills led to delays in obtaining refills.

"I think I didn't necessarily forget, I just forgot to pick up my prescription on time, so I missed the day in between the two. But other than that, I don't forget that one either."

\section{Costs}

Cost of treatment was a significant concern for 5 patients. They reported the reduced financial burden associated with taking fewer tablets and of weighing the value of paying for treatment when they were asymptomatic.

"I'd much rather pay than have to be symptomatic. But with symptoms going in remission I'd be more inclined probably to subside taking them and paying for them."

\section{Efficacy Values}

Patients who claimed not to see any benefits from their medications or were not convinced of their efficacy were less likely to adhere to their medication regimens: Why should I take it if I'm not seeing any benefits? Such patients wanted to see results for their actions. Also, some patients indicated that when they were in remission they did not feel the need to adhere as strictly to their regimens: "Why do I need to take it if I'm asymptomatic?"
At least 1 patient used the term "maintenance" in an almost dismissive manner, suggesting the medication was perceived as a less important class of drugs: "When I start feeling better or good, then I just am under the belief that I don't have to take the medication any more. So I just stop the medication."

\section{Side Effects}

Three patients reported experiencing adverse effects that they associated with their medications, which often prompted them to discontinue one medication and switch to another.

\section{Pill Characteristics}

A few patients made remarks about the characteristics of the pills themselves, such as pill size or frequency of dosing. If they experienced adverse effects that they associated with the medication, that often prompted them to discontinue one medication and switch to another: "If they were smaller that would be great. They're kind of like horse pills. I mean, they're pretty big."

Lastly, sometimes patients just don't feel like taking their medication: "Every once in a while I'm just sick of taking it."

\section{Discussion}

This qualitative research presents a comprehensive inventory of the key barriers to adherence from the perspective of the patient with chronic IBD. This is the first attempt to provide patient-level insights into the barriers to adherence in patients with IBD using focus groups and direct patient interviews. This process provides direct patient-reported factors, as has been recommended for the development of patient-reported outcomes for product development. ${ }^{28,29}$ Notably, this study highlights that nonadherence is driven by the interplay of multiple factors, including social stigma, competing daily priorities, efficacy beliefs, and refill inconvenience, that would require individualized interventions to address. The complexity of modern lifestyles appears to be a major barrier to multiple dosing regimens in these patients.

Our data, and other studies from patients with IBD and other chronic conditions, confirm that competing priorities in busy lifestyles are a barrier to medication adherence..$^{21,30,31}$ Our patient population is typically working or at college, which places medications among a long list of "things to do" on a daily basis. Our data also highlight that the impact of disruption to daily routines noted in other chronic conditions applies to the IBD population. ${ }^{32}$ The universal use of smart phones among this patient population has led to interest in electronic mechanisms to trigger medication adherence during daily activities, with promising short-term results. ${ }^{33}$ Other groups have used "intelligent" pill containers that remind patients if not opened. The finding in our study, however, that many patients report decanting their pills into various other storage solutions and locations may limit the utility of such devices. 
Since the "value" of the maintenance medication to patients' lives drives their ranking of it among all their daily tasks, that evaluation would suggest that enhancing patient perceptions of the benefits of maintenance therapy holds promise to improve adherence. Moshkovska et al. (2008) also reported that patients' self-evaluation of the benefits of medical therapy appears to impact whether patients accept or reject their maintenance medications. ${ }^{23}$ The impact of education or counseling to address this issue is uncertain. We previously reported that telephone counseling from trained nurses did not significantly improve objective measures of adherence, whereas others have reported that such phone calls improved patients' self-reports of adherence. ${ }^{12,14} \mathrm{~A}$ randomized controlled trial of educational and motivational interventions in patients with UC found that this approach maintained adherence but did not significantly improve it in baseline nonadherers. ${ }^{13,34}$ Further work is required to tailor motivational interventions to improve the priority of adherence in patients' lifestyles.

It is surprising in the age of electronic refills that the refill process is still perceived by patients as a burden, although this perception appears to be more prevalent among patients than providers. Preliminary data from other conditions suggest electronic refill requests from patients were one factor closely associated with $>90 \%$ medication adherence. ${ }^{35}$ The disconnect between issued prescriptions and pharmacy refills appears to be influenced by the time between refills. ${ }^{36}$ Finally, we found no substantial differences between UC and CD with respect to barriers to adherence, which is in line with other studies that report many more similarities than differences when comparing results by IBD diagnosis. ${ }^{18,21}$

\section{Limitations}

The sample size of this study was small and derived from a tertiary referral center, so inherent biases may have existed in the sampled population. Data from community practice patients with IBD were lacking. This study only focused on patients who were already prescribed maintenance therapy, so it provided data on the "implementation" phase of adherence behavior, rather than the "initiation" or "discontinuation" phases. ${ }^{37}$

\section{Conclusions}

This is the first study to present a qualitative description of the barriers to mesalamine adherence for patients with IBD. The themes identified in this article provide raw material for the improvement of existing patient-reported outcomes in IBD. The results of a recent review of IBD-specific measures suggested some important areas may be missing, particularly related to therapy. ${ }^{38}$ In addition, the themes highlighted in this study can be used to target tailored interventions to individuals with IBD to improve the complex attitudes around medication adherence.

\section{Authors}

JENNIFER DEVLEN, PhD, is Lead Outcomes Researcher, Patient Reported Outcomes, Oxford Outcomes, an ICON plc company, Bethesda, Maryland; KATHLEEN BEUSTERIEN, MPH, is Director, Outcomes Research Stategies in Health LLC, Washington, DC; and LINNETTE YEN, MA, MS, was Director, Global Health Economics and Outcomes Research, Global Medical Affairs, Shire, Wayne, Pennsylvania. AWAIS AHMED, MBBS, was Research Assistant; ADAM S. CHEIFETZ, MD, is Director, IBD Center; and ALAN C. MOSS, MD, is Associate Professor of Medicine, Center for Inflammatory Bowel Disease, Beth Israel Deaconess Medical Center, Boston, Massachusetts.

AUTHOR CORRESPONDENCE: Alan C. Moss, MD, Center for Inflammatory Bowel Disease, Beth Israel Deaconess Medical Center, 330 Brookline Ave., Boston, MA 022156. Tel.: 617.667.3197; Fax: 617.667.1171; E-mail: amoss@bidmc.harvard.edu.

\section{DISCLOSURES}

Funding for the patient interviews and focus groups was provided by Shire, in Wayne, Pennsylvania. The study design, implementation, and analysis were independent of the funding source. Moss was supported by NIH grant K23DK084338 and the generosity of Doris Toby Axelrod and Lawrence J. Marks. Moss has served on advisory boards for Janssen, Abbott, and Union Chemique Belge and received research funding from Shire, Salix, and Proctor $\&$ Gamble. Cheifetz has served on advisory boards for Janssen, Abbott, and Union Chemique Belge.

Interview planning, interviews, and transcript analysis were done by Devlen, Beusterien, Ahmed, and Moss. Patient enrollment was conducted by Ahmed, Cheifetz, and Moss. Study design was contributed by Devlen, Beusterien, Yen, and Moss. Data analysis and interpretation, as well as manuscript preparation, were performed by Devlen, Beusterien, and Moss. The guarantor of data integrity was Moss, and all authors read and approved the final manuscript.

\section{ACKNOWLEDGMENTS}

The authors and Shire gratefully acknowledge the valued scientific contribution of Linnette Yen. Linnette passed away on December 25, 2012, and will be dearly missed by the research teams to which she contributed or led.

The authors also thank Emuella Flood for assistance with the focus groups and patient interviews.

\section{REFERENCES}

1. Kane SV, Cohen RD, Aikens JE, Hanauer SB. Prevalence of nonadherence with maintenance mesalamine in quiescent ulcerative colitis. Am J Gastroenterol. 2001;96(10):2929-33.

2. Kane SV, Sumner M, Solomon D, Jenkins M. Twelve-month persistency with oral 5-aminosalicylic acid therapy for ulcerative colitis: results from a large pharmacy prescriptions database. Dig Dis Sci. 2011;56(12):3463-70.

3. Kane S, Huo D, Aikens J, Hanauer S. Medication nonadherence and the outcomes of patients with quiescent ulcerative colitis. Am J Med. 2003;114(1):39-43.

4. Kane S, Shaya F. Medication non-adherence is associated with increased medical health care costs. Dig Dis Sci. 2008;53(4):1020-24. 
5. Moody GA, Jayanthi V, Probert CS, MacKay H, Mayberry JF. Long-term therapy with sulphasalazine protects against colorectal cancer in ulcerative colitis: a retrospective study of colorectal cancer risk and compliance with treatment in Leicestershire. Eur J Gastroenterol Hepatol. 1996;8(12):1179-83.

6. Gifford AE, Berg AH, Lahiff C, Cheifetz AS, Horowitz G, Moss AC. A random urine test can identify patients at risk of mesalamine non-adherence: a prospective study. Am J Gastroenterol. 2013;108(2):249-55.

7. Kane S, Becker B, Harmsen WS, Kurian A, Morisky DE, Zinsmeister AR. Use of a screening tool to determine nonadherent behavior in inflammatory bowel disease. Am J Gastroenterol. 2012;107(2):154-60.

8. Lichtenstein GR, Rubin DT, Sabesin SM, Velayos FS, Vitat P. Maximizing patient adherence and clinical outcomes with mesalamine in mildly-to-moderately active ulcerative colitis. Rev Gastroenterol Disord. 2008;8(1):21-30.

9. Kane SV. Systematic review: adherence issues in the treatment of ulcerative colitis. Aliment Pharmacol Ther. 2006;23(5):577-85.

10. Kane SV. Overcoming adherence issues in ulcerative colitis. Gastroenterol Hepatol (NY). 2007;3(10):795-99.

11. Bender BG, Rankin A, Tran ZV, Wamboldt FS. Brief-interval telephone surveys of medication adherence and asthma symptoms in the Childhood Asthma Management Program Continuation Study. Ann Allergy Asthma Immunol. 2008;101(4):382-86.

12. Cook PF, Emiliozzi S, El-Hajj D, McCabe MM. Telephone nurse counseling for medication adherence in ulcerative colitis: a preliminary study. Patient Educ Couns. 2010;81(2):182-86.

13. Moshkovska T, Stone MA, Smith RM, Bankart J, Baker R, Mayberry JF. Impact of a tailored patient preference intervention in adherence to 5-aminosalicylic acid medication in ulcerative colitis: results from an exploratory randomized controlled trial. Inflamm Bowel Dis. 2011;17(9):1874-81.

14. Moss AC, Chaudhary N, Tukey M, et al. Impact of a patient-support program on mesalamine adherence in patients with ulcerative colitis-a prospective study. J Crohns Colitis. 2010;4(2):171-75.

15. Weinberger M, Murray MD, Marrero DG, et al. Effectiveness of pharmacist care for patients with reactive airways disease: a randomized controlled trial. JAMA. 288(13):1594-1602

16. Haynes RB, Ackloo E, Sahota N, McDonald HP, Yao X. Interventions for enhancing medication adherence. Cochrane Database Syst Rev. 2008;16(2):CD000011.

17. Demonceau J, Ruppar T, Kristanto P, et al. Identification and assessment of adherence-enhancing interventions in studies assessing medication adherence through electronically compiled drug dosing histories: a systematic literature review and meta-analysis. Drugs. 2013;73(6):545-62.

18. Ediger JP, Walker JR, Graff L, et al. Predictors of medication adherence in inflammatory bowel disease. Am J Gastroenterol. 2007;102(7):1417-26.

19. Yen L, Wu J, Hodgkins PL, Cohen RD, Nichol MB. Medication use patterns and predictors of nonpersistence and nonadherence with oral 5-aminosalicylic acid therapy in patients with ulcerative colitis. J Manag Care Pharm. 2012;18(9):701-12. Available at: http://amcp.org/WorkArea/ DownloadAsset.aspx?id=15874.

20. Wouters H, van Geffen EC, Baas-Thijssen MC, et al. Disentangling breast cancer patients' perceptions and experiences with regard to endocrine therapy: nature and relevance for non-adherence. Breast. 2013;22(5):661-66.

21. Cervený P, Bortlík M, Kubena A, Vlcek J, Lakatos PL, Lukás M.

Nonadherence in inflammatory bowel disease: results of factor analysis. Inflamm Bowel Dis. 2007;13(10):1244-49.
22. Gray WN, Denson LA, Baldassano RN, Hommel KA. Treatment adherence in adolescents with inflammatory bowel disease: the collective impact of barriers to adherence and anxiety/depressive symptoms. J Pediatr Psychol. 2012;37(3):282-91.

23. Moshkovska T, Stone M, Baker R, Mayberry J. Qualitative investigation of patient adherence to 5-aminosalicylic acid therapy in patients with ulcerative colitis. Inflamm Bowel Dis. 2008;14(6):763-68.

24. Love JR, Irvine EJ, Fedorak RN. Quality of life in inflammatory bowel disease. J Clin Gastroenterol. 1992;14(1):15-19.

25. Wolfe BJ, Sirois FM. Beyond standard quality of life measures: the subjective experiences of living with inflammatory bowel disease. Qual Life Res. 2008;17(6):877-86.

26. Chamberlain K, Camic P, Yardley L. Qualitative analysis of experience: grounded theory and case studies. In: Marks DF, Yardley L, eds. Research Methods for Clinical and Health Psychology. SAGE Publications, Thousand Oaks, CA; 2004:69-89.

27. Kerr C, Nixon A, Wild D. Assessing and demonstrating data saturation in qualitative inquiry supporting patient-reported outcomes research. Expert Rev Pharmacoecon Outcomes Res. 2010;10(3):269-81.

28. Lasch KE, Marquis P, Vigneux M, et al. PRO development: rigorous qualitative research as the crucial foundation. Qual Life Res. 2010;19(8):1087-96.

29. U.S. Department of Health and Human Services. Guidance for industry. Patient-reported outcome measures: use in medical product development to support labeling claims. 2009. Available at: http://www.fda.gov/downloads/ Drugs/Guidances/UCM193282.pdf. Accessed November 11, 2013.

30. Chambers SA, Raine R, Rahman A, Isenberg D. Why do patients with systemic lupus erythematosus take or fail to take their prescribed medications? A qualitative study in a UK cohort. Rheumatology (Oxford) 2009;48(3):266-71.

31. Gordon K, Smith F, Dhillon S. Effective chronic disease management: patients' perspectives on medication-related problems. Patient Educ Couns. 2007;65(3):407-15.

32. Vervloet M, Spreeuwenberg P, Bouvy ML, Heerdink ER, de Bakker DH, van Dijk L. Lazy Sunday afternoons: the negative impact of interruptions in patients' daily routine on adherence to oral antidiabetic medication: a multilevel analysis of electronic monitoring data. Eur J Clin Pharmacol. 2013;69(8):1599-606.

33. Vervloet M, van Dijk L, Santen-Reestman J, et al. SMS reminders improve adherence to oral medication in type 2 diabetes patients who are real time electronically monitored. Int J Med Inform. 2012;81(9):594-604.

34. Gifford A, Moss AC. Comment on Moshkovska et al. Inflamm Bowel Dis. 2013;19(2):E19.

35. Keith MD, Shimada SL, Rao SR, et al. Personal health record use and its association with antiretroviral adherence: survey and medical record data from 1,871 U.S. veterans infected with HIV. AIDS Behav. 2013;17(9):3091-100.

36. Acri T, TenHave TR, Chapman JC, Bogner HR, Gross R. Lack of association between retrospectively collected pharmacy refill data and electronic drug monitoring of antiretroviral adherence. AIDS Behav. 2010;14(4):748-54.

37. Vrijens B, De Geest S, Hughes DA, et al. A new taxonomy for describing and defining adherence to medications. Br J Clin Pharmacol. 2012;73(5):691-705.

38. Achleitner U, Coenen M, Colombel JF, Peyrin-Biroulet L, Sahakyan N, Cieza A. Identification of areas of functioning and disability addressed in inflammatory bowel disease-specific patient reported outcome measures. J Crohns Colitis. 2012;6(5):507-17. 